\title{
Targeting protein arginine methyltransferase 5 inhibits human hepatocellular carcinoma growth via the downregulation of beta-catenin
}

\author{
Baolai Zhang ${ }^{1 * \dagger}$, Shuhong Dong ${ }^{1 \dagger}$, Zhongxin Li ${ }^{2}$ Li Lu' , Su Zhang ${ }^{1}$, Xue Chen ${ }^{1}$, Xiaobo Cen ${ }^{3}$ and Yongjie Wu ${ }^{1 *}$
}

\begin{abstract}
Background: Protein arginine methyltransferase 5 (PRMT5), a type II PRMT, is highly expressed in some tumors, but its role in hepatocellular carcinoma (HCC) is still unknown.

Methods: PRMT5 level in HCC specimens was determined by immunohistochemical staining and the association with clinicopathologic features was evaluated. PRMT5 was inhibited by AMI-1 (a small molecule inhibitor of PRMTs) or small interference RNA (siRNA). The proliferation of HCC cells was tested by Cell Counting Kit-8, cell migration was evaluated by Transwell assay and cell cycle and apoptosis were analyzed by flow cytometry. The effect of AMI-1 on HCC in vivo was examined by mouse xenograft model.

Results: PRMT5 expression was markedly upregulated in HCC tissues, and correlated inversely with overall patient survival. Knockdown of PRMT5 significantly reduced the proliferation of HCC cells, but did not affect the growth of normal liver cells. Furthermore, $\beta$-catenin was identified as a target of PRMT5. Silencing PRMT5 significantly down-regulated the expression of $\beta$-catenin and the downstream effector Cyclin D1 in HCC cells. AMI-1 strongly inhibited HCC growth in vivo, increased the ratio of Bax/BCl-2, and led to apoptosis and loss of migratory activity in several HCC cells. Meanwhile, AMI-1 decreased the expression levels of symmetric dimethylation of H4 (H4R3me2s), a histone mark of PRMT5.
\end{abstract}

Conclusions: PRMT5 plays an important role in HCC. PRMT5 may be a promising target for HCC therapy.

Keywords: PRMT5, HCC, $\beta$-Catenin, AMI-1, H4R3, H3R8 methylation

\section{Background}

Hepatocellular carcinoma (HCC) is the fifth leading cancer and the third most common cause for cancer death worldwide [1-3]. The overall survival of patients with $\mathrm{HCC}$ is less than $10 \%$. Surgical resection and liver transplantation is the main therapeutic strategy for HCC if patients are diagnosed at an early stage [4]. However, a majority of patients with HCC present with advanced

\footnotetext{
*Correspondence: zhangb|@|zu.edu.cn; wuyj@|zu.edu.cn

${ }^{\dagger}$ Baolai Zhang and Shuhong Dong contributed equally to this work

${ }^{1}$ Department of Pharmacology, School of Basic Medical Sciences, Lanzhou University; Key Lab of Preclinical Study for New Drugs of Gansu Province, No 199, Dongang West Road, Lanzhou 730000, Gansu, China Full list of author information is available at the end of the article
}

disease and treatment options are limited [5]. Sorafenib has been recognized as the most effective targeted therapeutic agent for advanced HCC. However, compared with placebo groups, sorafenib only increased survival from 7.9 to 10.7 months [6]. Therefore, it is urgent to develop more effective therapeutic strategies and agents to treat HCC.

Protein arginine methyltransferase 5 (PRMT5), a type II arginine methyltransferase, is localized in both cytoplasm and the nucleus of mammalian cells $[7,8]$. PRMT5-driven methylation of arginine residues leads to symmetric dimethylation of histone H3 (H3R8me2s) and H4 (H4R3me2s), which in turn alter chromatin structure to regulate gene expression $[9,10]$. PRMT5 
has been found to be overexpressed in multiple tumor types, including leukemia, lymphoma, lung cancer, colorectal cancer and breast cancer [11-15]. However, the role of PRMT5 in hepatocarcinogenesis has not been established.

In this study we aimed to investigate the role of PRMT5 in hepatocarcinogenesis by using in vitro and in vivo models. We showed that PRMT5 protein is overexpressed in HCC tumor tissues, and its elevated level is associated with worse prognosis in patients with HCC. In addition, we found that specific deletion of PRMT5 by small interference RNA (siRNA) or the inhibition of its activity by arginine methyltransferase inhibitor 1 (AMI-1) significantly decreases HCC development. Furthermore, we demonstrate that the deletion of PRMT5 significantly down-regulates the expression of $\beta$-catenin and its downstream effector Cyclin D1 in HCC cells.

\section{Methods}

\section{Human tissue samples and cell lines}

Fifty-four pairs of HCC tissues and corresponding normal adjacent tissues (NATs) were purchased from the National Engineering Center for Biochips (Shanghai, China). All human materials were obtained with informed consent, and this study was approved by Ethics Committee of Lanzhou University. Four human HCC cell lines (HepG2, Bel-7404, Bel-7402 and SMMC-7721), one rat hepatoma cell line CBRH-7919 and one normal liver cell line HL-7702 were purchased from American Type Culture Collection (Manassas, VA, USA), and cultured under conditions recommended.

\section{Immunohistochemical staining}

Tissue arrays were constructed using 54 pairs of $\mathrm{HCC}$ tissues and corresponding NATs. Immunohistochemical staining was performed on $4 \mu \mathrm{m}$ sections of paraffinembedded human HCC tissues and matched NATs to determine the expression level of PRMT5 protein. Briefly, the slides were incubated with PRMT5 antibody at $4{ }^{\circ} \mathrm{C}$ overnight. After extensive washing, the sections were incubated with secondary antibody, followed by staining with DAB (ZSGB-BIO, Beijing, China). The slides were then washed and counterstained with hematoxylin. A semiquantitative scoring method according to the overall staining of the cells was applied for immunohistochemistry (IHC) $[16,17]$.

\section{RNA interference}

Three different siRNA each were synthesized against human PRMT5 by Ribobio (Guangzhou, China), and the most effective one (target sequence: CCGCTATT GCACCTTGGAA) was selected for the subsequent experiments with test siRNA. Cells were transfected with
PRMT5 siRNA (si-PRMT5, final concentration of $50 \mathrm{nM}$ ) or scramble siRNA (Negative control siRNA, si-NC) using Lipofectamine 2000 (Invitrogen, Carlsbad, CA, USA) according to manufacturer's protocol.

\section{Cell proliferation assay and colony formation assay}

Cells were seeded in flat-bottom 96-well plates $\left(2.5 \times 10^{3}\right.$ cells per well) in triplicate. After $24 \mathrm{~h}$, cells were treated with si-NC, si-PRMT5 or AMI-1. Then cell proliferation was assessed using the Cell Counting Kit-8 (Dojindo, Tokyo, Japan) according to the manufacturer's protocols. The efficacy of the treatment was expressed as best tumor growth inhibition $[18,19]$. The $T / C$ value was calculated as follows: $\% T / C=$ (median tumor weight of treated tumors/median tumor weight of control tumors) $\times 100$. For the colony formation assay, HepG2 and HL-7702 cells were placed in $60 \mathrm{~mm}$ dishes at 200 cells per dish and maintained in the absence or presence of si-PRMT5 for 16 days. Cells were fixed with fixative (7 parts methanol: 1 part glacial acetic acid) for $15 \mathrm{~min}$ and then stained with crystal violet $(0.2 \mathrm{~g} / \mathrm{L})$ for $30 \mathrm{~min}$.

\section{Cell cycle analysis and apoptosis assay}

Cell cycle and apoptosis were analyzed by flow cytometry as described previously [20,21]. Briefly, cells were seeded at $1 \times 10^{5}$ cells/well in 6-well plates and transfected with si-NC or si-PRMT5. After $72 \mathrm{~h}$, cells were harvested using $0.25 \%$ trypsin without EDTA and fixed in $75 \%$ ethyl alcohol at $-20{ }^{\circ} \mathrm{C}$ overnight. The next day, cells were exposed to $40 \mathrm{mg} / \mathrm{ml}$ propidium iodide and $100 \mathrm{mg} /$ $\mathrm{mL}$ ribonuclease A in PBS for $30 \mathrm{~min}$ at room temperature in the dark. Cell DNA content was then analyzed using FACS. For apoptosis assay, the treated cells were harvested using $0.25 \%$ trypsin, washed twice and resuspended in Binding Buffer at concentration of $1 \times 10^{6}$ cells $/ \mathrm{mL}$. $500 \mu \mathrm{L}$ of cells were incubated with $5 \mu \mathrm{L}$ of Annexin V-FITC and $5 \mu \mathrm{L}$ of Propidium Iodide for $5 \mathrm{~min}$ at room temperature in the dark. The samples were then evaluated by FACS (Navios, Beckman Coulter, CA, USA).

\section{Western blot analysis}

Cell lysates were separated in $12 \%$ SDS-polyacrylamide gel electrophoresis, and then transferred to PVDF membrane (Bio-Rad). After being blocked with $5 \%$ non-fat milk for $1 \mathrm{~h}$, the membranes were incubated with the following primary antibodies at $4{ }^{\circ} \mathrm{C}$ overnight: PRMT5 (1:400; Santa Cruz Biotech, Santa Cruz, CA, USA), PRMT7 (1:500; Santa Cruz Biotech), Cyclin D1 (1:500; Santa Cruz Biotech), CTNNB1 ( $\beta$-catenin, 1:1000; ABclonal, MA, USA), H4R3me2s (1:2000; Abcam, MA, USA), H3R8me2s (1:250; Novus, CO, USA), Bax (1:1000; Cell Signaling, MA, USA), Bcl-2 (1:1000; Cell Signaling), PRMT7 (1:1000; Cell Signaling) or $\beta$-actin 
(1:2000; Cell Signaling), and then incubated with secondary antibodies conjugated to horseradish peroxidase (ZSGB-BIO, Beijing, China). Immuno-reactivity was visualized using ECL Western blotting detection reagents and then analyzed by densitometry.

\section{Migration assay}

Cell migration assay was performed in 24-well transwell chambers, $8 \mu \mathrm{m}$ pore size Transwell plate (Corning Inc.; NY, USA) [22, 23]. In brief, the cells resuspended in $100 \mu \mathrm{L}$ serum-free medium $\left(4 \times 10^{4}\right.$ cells per well $)$ were placed in upper chamber of insert in triplicate and medium with $600 \mu \mathrm{L} 10 \%$ FBS was used as chemoattractant in lower chamber. AMI-1 or vehicle control was added to inner chamber. After $24 \mathrm{~h}$, the cells remaining on the top surface of the membrane were removed with a cotton swab. The cells on the bottom surface of the membrane were fixed in methanol and stained with $0.2 \%$ crystal violet.

\section{Human HCC xenograft model}

Female athymic BALB/c nude mice were purchased from Shanghai SLAC Laboratory Animal Co. Ltd (Shanghai, China) and maintained under specific pathogen-free room with a 12-h on/off light cycle, and fed autoclaved chow and water. Mice were manipulated and housed according to protocols approved by the Institutional Animal Care and Treatment Committee of Lanzhou University. $5 \times 10^{6}$ HepG2 cells were inoculated subcutaneously (s.c) in the right flank of 5-6-week old healthy BALB/c nude mice. When tumors reached an average volume of about $70 \mathrm{~mm}^{3}$, the mice bearing too large or too small tumors were eliminated and the left were randomly divided into two treatment groups (8 animals per group): AMI- $1(0.5 \mathrm{mg}$ in $100 \mu \mathrm{L}$ of $0.9 \% \mathrm{NaCl})$ or $100 \mu \mathrm{L}$ of $0.9 \% \mathrm{NaCl}$ were administered intratumorly (i.t) twice a week. Control animals and animals treated with AMI-1 were sacrificed after 36 days and tumor were excised and weighted. Tumor volumes were calculated according to the following formula: $\left(\right.$ length $\left.\times w i d t h^{2}\right) \times 0.52$.

\section{Statistical analysis}

Unless otherwise stated, data were presented as the mean \pm SD and subjected to student's $t$ test. Differences were considered statistically significant as ${ }^{*} P<0.05$, ** $P<0.01$ or ${ }^{* * *} P<0.001$.

\section{Results}

\section{PRMT5 is overexpressed in primary HCC tumors}

To evaluate the clinical significance of PRMT5 in HCC development, we analyzed PRMT5 level and its distribution in HCC tissues by immunohistochemical (IHC) staining. The array included the cancer tissue samples and corresponding normal adjacent tissues (NATs) from 54 HCC patients, which consisted of 48 males and 6 females, with a medium age of 53 years (range 38-72 years). Among the patients 31 (57.4 \%) died of tumor related to causes, and 23 (42.6\%) were still alive as of the last follow-up (Table 1). PRMT5 levels in the tissues array specimens were assessed based on the staining density scores. We found that in cancer tissues, 31 cases $(57.4 \%)$ exhibited strong immunopositivity, 18 cases (33.3 \%) exhibited moderate immunopositivity, and 5 cases $(9.3 \%)$ exhibited no or weak immunopositivity. In contrast, the majority of normal tissues (51.9 \%) exhibited no or weak PRMT5 expression (Table 2). Statistical analysis revealed that PRMT5 level significantly increased in cancer tissues compared with the corresponding NATs (Fig. 1A, B). In addition, cytoplasmic PRMT5 level, but not nuclear PRMT5 level, had a trend to be negatively correlated with the survival rate of the patients with HCC (Fig. 1C). As negative control, PRMT5 antibody could not detect positive staining (Additional file 1: Figure 1). Notably, no significant association was found between PRMT5 expression in

\begin{tabular}{|c|c|c|c|c|}
\hline Characteristics & $\mathrm{n}$ & $\%$ & $\begin{array}{l}\text { PRMT5 } \\
\text { score }\end{array}$ & $P$ value \\
\hline \multicolumn{5}{|l|}{ Gender } \\
\hline Male & 48 & 88.9 & 3.8542 & \multirow[t]{2}{*}{0.369} \\
\hline Female & 6 & 11.1 & 3.3333 & \\
\hline \multicolumn{5}{|l|}{ Age (years) } \\
\hline$\leq 50$ & 17 & 31.5 & 3.2059 & \multirow[t]{2}{*}{0.034} \\
\hline$>50$ & 37 & 68.5 & 4.0135 & \\
\hline \multicolumn{5}{|l|}{ Tumor size (cm) } \\
\hline$\leq 5$ & 27 & 50 & 3.8611 & \multirow[t]{2}{*}{0.573} \\
\hline$>5$ & 27 & 50 & 3.6574 & \\
\hline \multicolumn{5}{|l|}{ TNM stage } \\
\hline I & 6 & 11.1 & 4.0833 & \multirow[t]{3}{*}{0.259} \\
\hline$\|$ & 37 & 68.5 & 3.6757 & \\
\hline |l & 11 & 20.4 & 8.8636 & \\
\hline
\end{tabular}

Table 2 Summary of PRMT5 scoring distribution

\begin{tabular}{lll}
\hline Composite score & $\begin{array}{l}\text { Normal liver } \\
\text { tissue }(\mathbf{n}=\mathbf{5 4})\end{array}$ & $\begin{array}{l}\text { HCC tissue } \\
(\mathbf{n}=\mathbf{5 4})\end{array}$ \\
\hline$<2$ (weak immunopositivity) & $28(51.9 \%)$ & $5(9.3 \%)$ \\
$2-4$ (moderate immunopositivity) & $22(40.7 \%)$ & $18(33.3 \%)$ \\
$\geq 4$ (strong immunopositivity) & $4(7.4 \%)$ & $31(57.4 \%)$ \\
P values & & $<0.0001$ \\
\hline
\end{tabular}

$P$ value calculated by $X^{2}$ test for normal liver tissue versus HCC tissue 
HCC and tumor size or TNM stage $(P>0.05$, Table 1$)$. Univariate Cox regression analyses showed that PRMT5 expression in the cytoplasm was significantly correlated with overall survival (Table 3). Furthermore, multivariate Cox regression analysis confirmed that cytoplasmic PRMT5 expression could serve as independent predictor of the overall survival of patients with HCC (Table 3). In addition, we performed Western blot analysis to determine of PRMT5 protein level in several HCC cell lines. As shown in Additional file 1: Figure 2, PRMT5 was expressed in normal liver HL-7702 cells and highly expressed in Bel-7704, HepG2 and CBRH-7919 HCC cell lines. Taken together, these results indicate that PRMT5 overexpressed is tightly linked to HCC proliferation and development.

\section{Knockdown of PRMT5 suppresses HCC cell proliferation in vitro}

To determine the role of PRMT5 in HCC cell proliferation, we employed siRNA against human PRMT5 to knockdown PRMT5 in two human HCC cells (HepG2 and Bel-7404) and one normal liver cell (HL-7702), and then cell proliferation was measured by CCK- 8 assay. As shown in Fig. 2a-c, silencing PRMT5 significantly decreased proliferation and colony formation of HCC cells, but not normal hepatocyte HL-7702. In addition, because PRMT5 and PRMT7 have been shown to possess type II methyltransferase activity [24, 25], we tested the specificity of si-PRMT5 in HCC cell lines. The results showed that si-PRMT5 did not affect the protein levels of PRMT7 (data not shown).

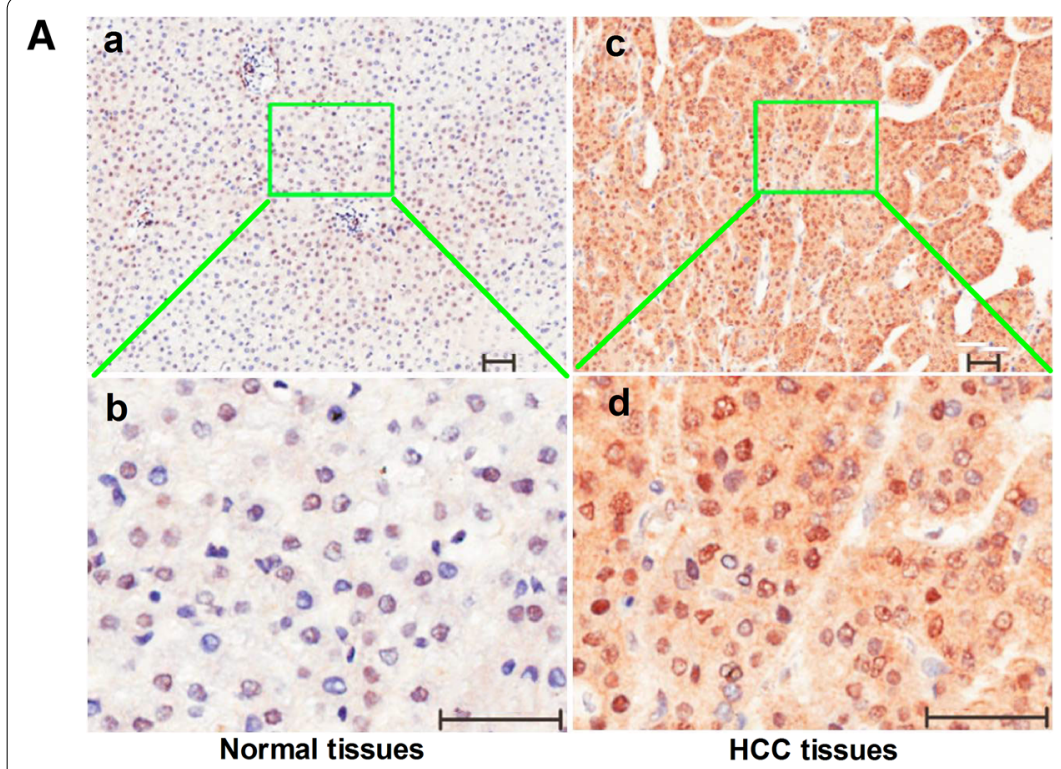

B

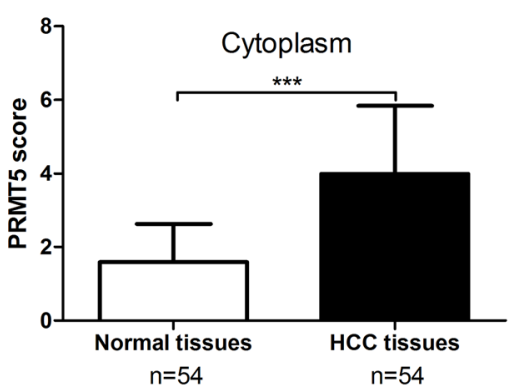

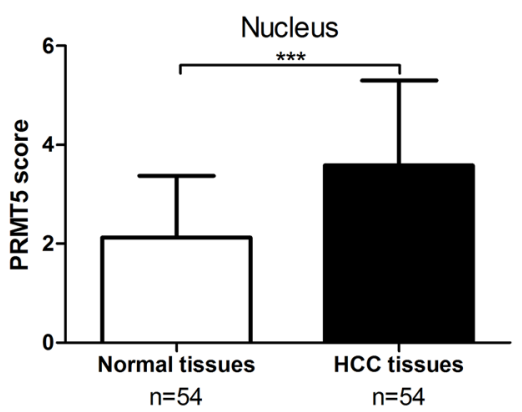

C

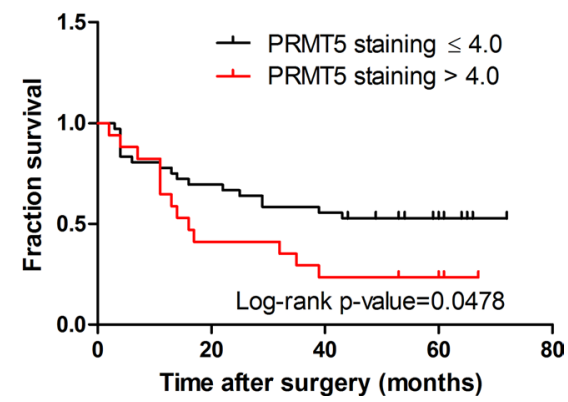

Fig. 1 Upregulation of PRMT5 in HCC tissues and its association with poor survival. A Immunohistochemical staining of PRMT5 in HCC tissues and corresponding NATs. Positive cells were stained brown. Magnification, $(a, c) \times 50 ;(b, d) \times 100$; scale bar $50 \mu$ m. B PRMT5 scores based on the nuclear or cytoplasmic levels of expression in 54 HCC patients, compared with matched normal tissues. C Association between PRMT5 expression and the survival of HCC patients 
Table 3 Univariate and multivariate analyses of the survival of HCC patients

\begin{tabular}{|c|c|c|c|c|c|c|c|}
\hline \multirow[t]{2}{*}{ Covariate } & \multirow[t]{2}{*}{$\mathrm{n}$} & \multicolumn{3}{|c|}{ Univariate analysis } & \multicolumn{3}{|c|}{ Multivariate analysis } \\
\hline & & HR & $95 \% \mathrm{Cl}$ & $P$ value & HR & $95 \% \mathrm{Cl}$ & $P$ value \\
\hline Gender & & & & 0.710 & & & 0.758 \\
\hline Male & 48 & 1.000 & & & 1.000 & & \\
\hline Female & 6 & 1.254 & $0.381-4.126$ & & 1.232 & $0.326-4.654$ & \\
\hline Age (years) & & & & 0.812 & & & 0.371 \\
\hline$\leq 50$ & 17 & 1.000 & & & 1.000 & & \\
\hline$>50$ & 37 & 1.099 & $0.506-2.387$ & & 0.671 & $0.280-1.609$ & \\
\hline Tumor size (cm) & & & & 0.037 & & & 0.062 \\
\hline$\leq 5$ & 27 & 1.000 & & & 1.000 & & \\
\hline$>5$ & 27 & 2.170 & $1.046-4.504$ & & 2.148 & 0.964 & 4.785 \\
\hline TNM stage & & & & 0.105 & & & 0.329 \\
\hline 1 & 6 & 1.000 & & & 1.000 & & \\
\hline$\|$ & 37 & 1.087 & $0.323-3.659$ & & & & \\
\hline III & 11 & 2.395 & $0.633-9.058$ & & 1.459 & $0.683-3.116$ & \\
\hline Cytoplasmic PRMT5 & & & & 0.033 & & & 0.029 \\
\hline Low & 36 & 1.000 & & & 1.000 & & \\
\hline High & 18 & 2.175 & $1.067-4.435$ & & 2.411 & $1.094-5.313$ & \\
\hline Nuclear PRMT5 & & & & 0.963 & & & 0.691 \\
\hline Low & 40 & 1.000 & & & 1.000 & & \\
\hline High & 14 & 1.020 & $0.439-2.369$ & & 1.228 & $0.446-3.380$ & \\
\hline
\end{tabular}

The Cox proportional hazards regression model was used for univariate and multivariate analyses to study the effects of the clinicopathological variables and PRMT5 expression on survival

$H R$ hazard ratio, $\mathrm{Cl}$ confidence interval

\section{Knockdown of PRMT5 induces HCC cell cycle arrest}

To explore the mechanism by which PRMT5 knockdown inhibits HCC cell proliferation, we performed cell cycle analysis. As shown in Fig. 2d, PRMT5 knockdown led to an increase of cell population at the G1 phase, with a corresponding decrease in $\mathrm{S}$ and G2/M phase, compared with si-NC, indicating that PRMT5 may be required for the G1-to-S phase transition.

To understand underlying mechanism of cell cycle arrest, the levels of several cell proliferation/cyclerelated proteins in si-NC and PRMT5-knockdown HCC cells were analyzed by Western blot analysis. As shown in Fig. 2e, knockdown of PRMT5 significantly decreased the expression of $\beta$-catenin and Cyclin D1 in HCC cells. These results indicate that PRMT5 promotes cell cycle progression by regulating the expression of cell cycle-related proteins such as $\beta$-catenin and Cyclin D1.

Because PRMT5-driven methylation of arginine residues leads to H4R3me2s and H3R8me2s, we then measured H4R3me2s and H3R8me2s in HCC cells treated with si-PRMT5. We found that the levels of H4R3me2s and H3R8me2s were significantly decreased compared with si-NC (Fig. 2f).
AMI-1 inhibits HCC cell proliferation in vitro and in vivo AMI-1 has been applied to inhibit type I PRMT (PRMT1, 3,4 , and 6) activity in vitro [26]. Interestingly, we found that AMI-1 also inhibited $84.2 \%$ of type II PRMT5 activity at the tested concentration (nearly $50 \mu \mathrm{M}$ ) [27]. Therefore, we examined the in vitro and in vivo efficacy of AMI-1 on HCC using human HCC cell lines and xenograft mouse models. The concentrations of AMI-1 used for in vitro and in vivo experiments and for enzymatic assay are different, based on our preliminary experiments and previous literatures [27-30]. As shown in Fig. 3a, AMI-1 elicited a significant inhibition on HCC cell growth. In animal tumor models, the tumors were injected with AMI-1 intratumorly (i.t.), because the drug via systemic delivery is easily denatured or degraded. We found that treatment with AMI-1 reduced tumor weight by $65.1 \%$ compared with control-treated animals (Fig. 3b).

\section{AMI-1 inhibits PRMT5 activity and induces apoptosis in HCC cells}

To further explore the mechanism of PRMT5 action in HCC, Western blot analysis was performed to determine protein levels of Bax and Bcl-2 in HCC cells. The results 

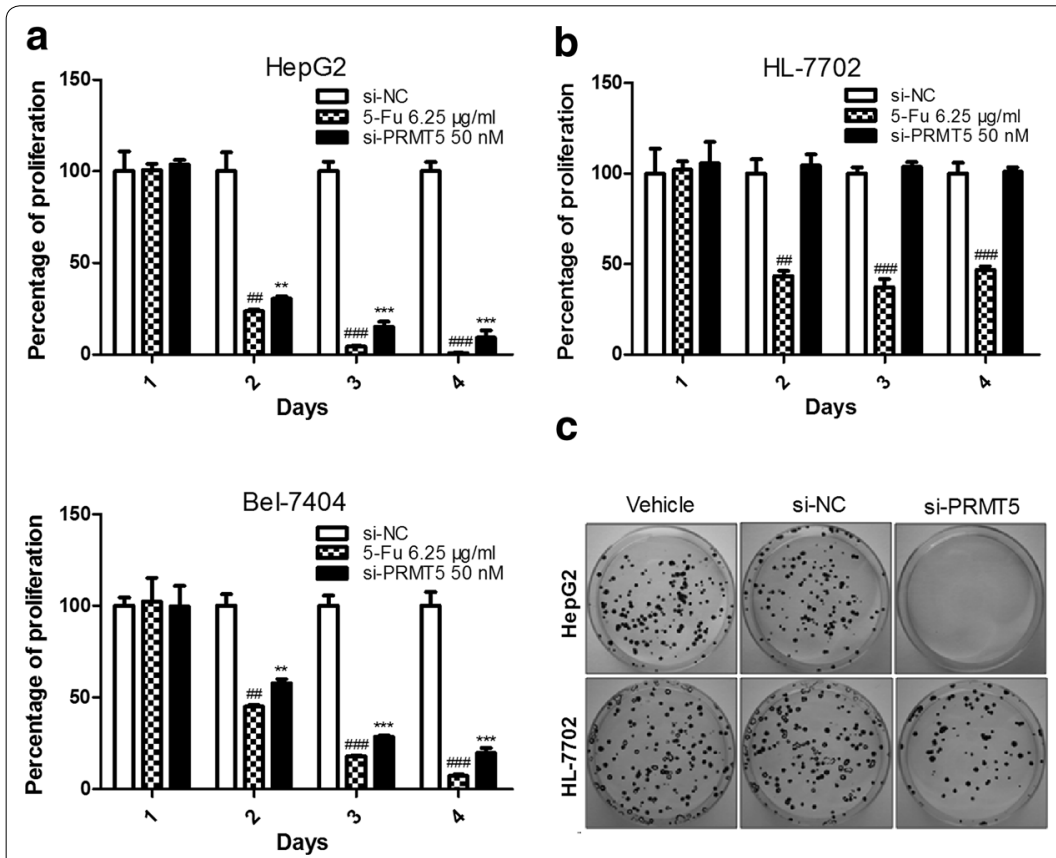

e
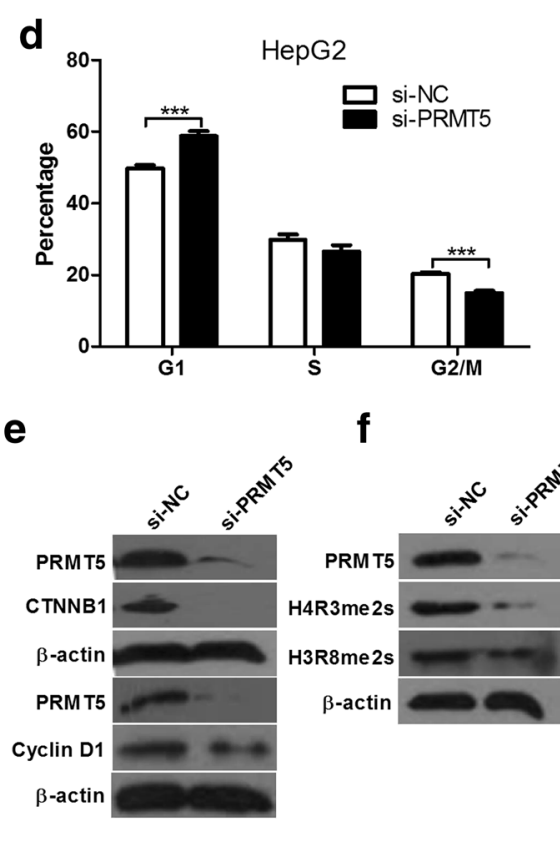

Fig. 2 Silencing PRMT5 decreases human HCC cell growth in vitro. a HepG2 and Bel-7404 cells were transfected with PRMT5 siRNA (si-PRMT5) or scramble negative control siRNA (si-NC) and cell proliferation was analyzed. b Normal liver HL-7702 cells were transfected with PRMT5 siRNA (siPRMT5) or scramble negative control siRNA (si-NC) and cell proliferation was analyzed. c The effect of si-PRMT5 on colony formation of HepG2 and HL-7702 cells. Representative results of colony formation of vehicle (left), si-NC (middle), and si-PRMT5 (right) HepG2 and HL-7702 cells. 5-fluorouracil (5-Fu) is used as a positive control. d Knockdown of PRMT5 led to G1 arrest. HepG2 cells were transfected with si-NC or si-PRMT5 and then subjected to cell cycle analysis. e and $\mathbf{f}$ Western blot analysis of whole-cell lysates derived from HepG2 cells transfected with si-NC or si-PRMT5 using antibodies against PRMT5, $\beta$-catenin, Cyclin D1, H4R3me2s or H3R8me2s

showed that AMI-1 increased Bax/Bcl-2 ratio associated with apoptosis relative to control cells (Fig. 3c). As shown in Fig. 3c, d, the expression of H4R3me2s protein was significantly decreased in AMI-1 treated cells compared with control cells. These results indicate that AMI-1 inhibits HCC growth, at least partially through inhibiting PRMT5 activity in HCC cells.

\section{PRMT5 inhibition promotes the apoptosis while inhibits the migration of HCC cells}

Inhibition of PRMT5 overexpression can induce apoptosis in different types of cancer [24,31,32]. To investigate the effect of AMI-1 on HCC cell viability, Bel-7402 and HepG2 cells were treated with either AMI-1 or vehicle only, and apoptosis was determined by Annexin V-FITC/ propidium iodide staining and flow cytometry. As shown in Fig. 4a, PRMT5 inhibition by AMI-1 resulted in the induction of apoptosis/death in both cells compared with control cells. In addition, transwell assay showed that treatment of HCC cells with AMI-1 resulted in marked reduction in migration activity compared with control group (Fig. 4b). Furthermore, we employed siRNA to knockdown PRMT5 in HCC cells and found that PRMT5
siRNA increased the apoptosis while decreased the migration of HCC cells (Additional file 1: Figure 3).

\section{Discussion}

PRMT5 emerges as an important regulator of multiple cellular processes and is expressed aberrantly in different types of cancer [11-15]. However, the role of PRMT5 in the pathogenesis of HCC and the relationship between PRMT5 expression and clinicopathological factors of HCC are largely unknown. In this study, we found that PRMT5 expression was markedly up-regulated in HCC tissues compared with NATs, and that higher expression of PRMT5 in the cytoplasm was significantly correlated with poor prognosis of HCC patients. Furthermore, we demonstrated that PRMT5 knockdown by siRNA could significantly inhibit the proliferation and colony formation of HCC cells, and repress cell cycle progression by inducing G0/G1 cell cycle arrest. Collectively, these data indicate that PRMT5 may function as an oncogene and is a key mediator in carcinogenesis and progression of HCC.

Wnt $/ \beta$-catenin signaling is frequently activated in HCC, but the causes of its activation are not well 


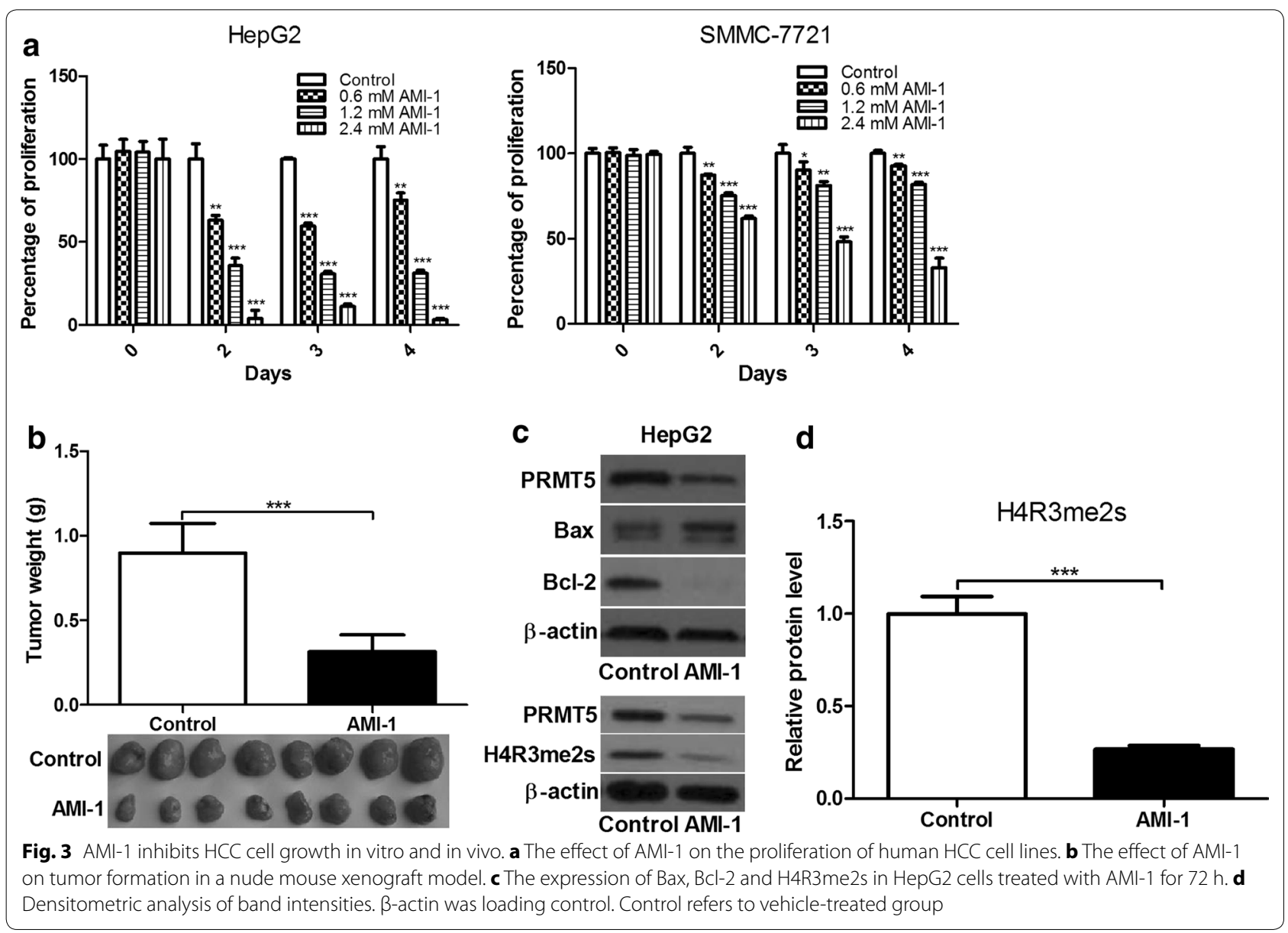

understood [33]. Cytoplasmic and nuclear accumulations of $\beta$-catenin occur in $40-70 \%$ of HCCs [34]. Upon Wnt activation, accumulated $\beta$-catenin enters the nucleus and binds to T-cell factor/lymphoid enhancer factor (TCF/ LEF) to activate the transcription of Wnt target genes $[35,36]$. A key event in both Wnt signaling and cancer cell proliferation is the regulation of $\beta$-catenin stability and activity. Our results showed that silencing PRMT5 significantly attenuates the expression levels of $\beta$-catenin and Cyclin D1. As Cyclin D1 is a downstream target of $\mathrm{Wnt} / \beta$-catenin pathway and plays a key role as a regulator of cell proliferation [37], these data suggest that PRMT5 might mediate HCC tumor proliferation and development by regulating Cyclin D1 through Wnt/ $\beta$ catenin pathway. This finding also suggests that PRMT5 mediated methylation is bi-functional, either repressing or promoting transcription, depending on what genes are expressed [38]. Additional studies will be required to distinguish the multiple potential mechanisms for PRMT5 function in different events of gene expression regulation.

There are several strategies to inhibit PRMT5 overexpression in cancer. In this study, we demonstrated that knockdown of PRMT5 by siRNA effectively inhibited HCC cell proliferation and colony formation in vitro, but treatment with siRNA is still in the experimental stage $[39,40]$. Moreover, as no specific potent inhibitors are yet available for members of the PRMT enzyme family [25], our efforts focus on the discovery and development of small molecule inhibitors of PRMT5. AMI-1, a symmetrical sulfonated urea, was discovered by Cheng et al. [26]. However, AMI-1 has been applied to inhibit type I PRMT activity only in vitro experiments.

PRMTs are classified as either type I or type II. Both types can catalyze the formation of omega-N monomethylarginine (MMA) as an intermediate, and type I PRMTs (PRMT1, PRMT3, PRMT4, and PRMT6) lead to the production of asymmetrical dimethylarginine (aDMA), whereas type II PRMTs (PRMT5 and PRMT7) catalyze the formation of symmetrical dimethylarginine (sDMA) [41]. In this study, we first demonstrated that AMI-1 inhibited HCC growth in vitro and in vivo. Furthermore, we detected the expression of apoptosis related proteins such as Bax and Bcl-2 and found that AMI-1 up-regulated $\mathrm{Bax} / \mathrm{Bcl}-2$ ratio in $\mathrm{HCC}$ cells. AMI-1 also induced 


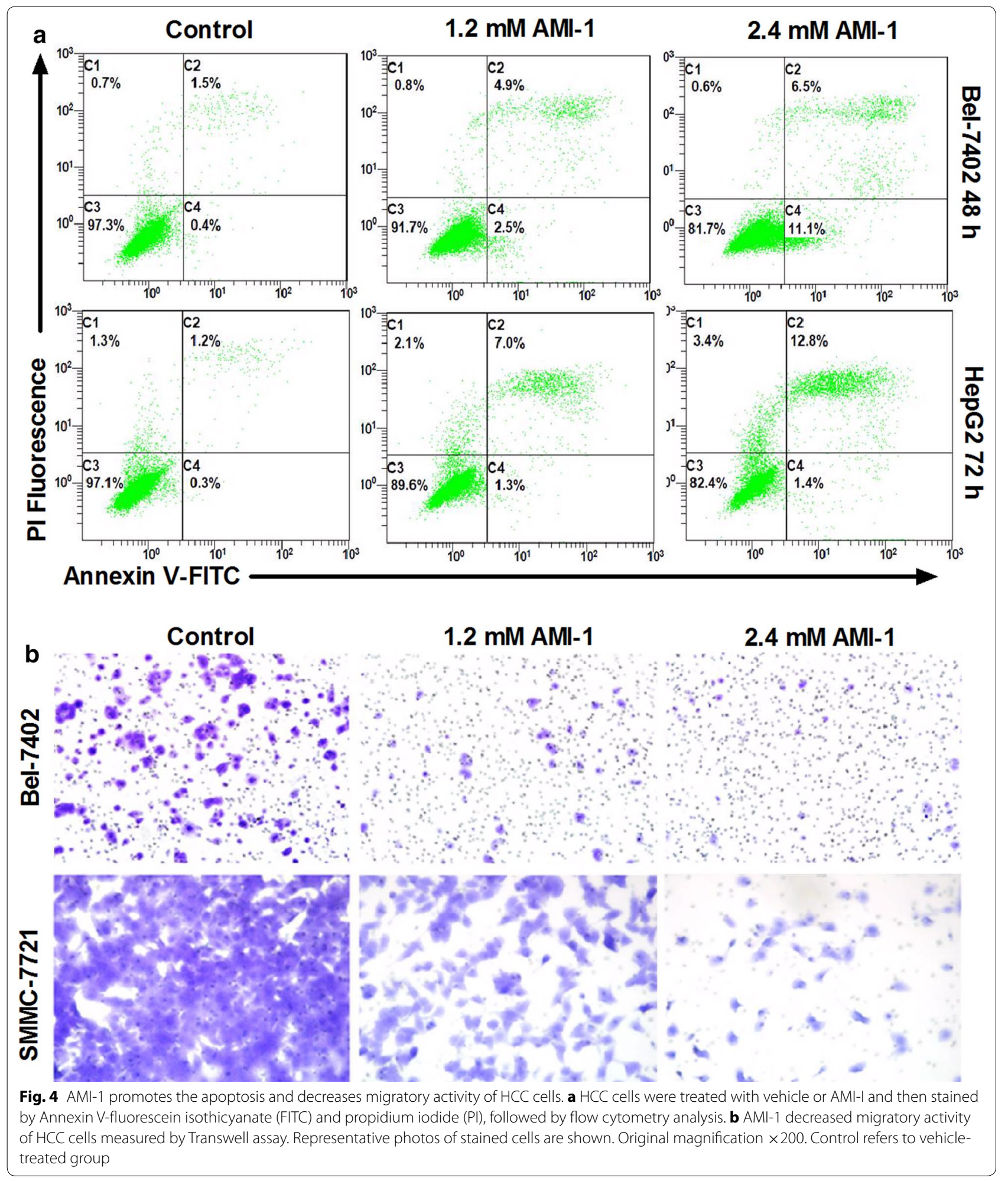

apoptosis and decreased migratory activity in several HCC cell lines. In addition, AMI-1 decreased the expression levels of H4R3me2s, a histone marker of PRMT5.
These data suggest that AMI-1 exhibits anti-tumor effects against $\mathrm{HCC}$, at least in part through inhibitting PRMT5. 


\section{Conclusion}

These results strongly indicate that PRMT5 is frequently up-regulated and inversely correlated with poor prognosis in HCC patients. PRMT5 might function as an oncogene partly by mediating the repression of $\beta$-catenin and its downstream target Cyclin D1 in HCC. Therefore, PRMT5 might be a potential biomarker and a promising therapeutic target for $\mathrm{HCC}$.

\section{Additional file}

Additional file 1: Figure 1. Immunostaining of PRMT5 in normal and HCC tissue. In Negative control PRMT5 antibody was replaced with PBS. Figure 2. The endogenous expression level of PRMT5 in HCC cell lines and normal liver cell line. Figure 3. The effects of si-PRMT5 on the apoptosis and migration of HCC cells.

\section{Authors' contributions}

BLZ and SHD designed methods and experiments, carried out the laboratory experiments and wrote the paper. ZXL participated in collecting data and writing manuscript. LL collected experimental data and analyzed the data. SZ collected experimental data and wrote the manuscript. XC participated in collecting experimental data. XBC and YJW gave scientific advice. All authors read and approved the final manuscript.

\section{Author details}

${ }^{1}$ Department of Pharmacology, School of Basic Medical Sciences, Lanzhou University; Key Lab of Preclinical Study for New Drugs of Gansu Province, No 199, Dongang West Road, Lanzhou 730000, Gansu, China. ${ }^{2}$ Gansu Provincial Second People's Hospital, Lanzhou 730000, China. ${ }^{3}$ State Key Laboratory of Biotherapy and Cancer Center, West China Hospital, Sichuan University, and Collaborative Innovation Center for Biotherapy, Chengdu 610041, China.
\end{abstract}

\section{Acknowledgements}

This study was supported by Fundamental Research Funds of the Central Universities (No. Izujbky-2013-169 and No. Izujbky-2013-171).

\section{Competing interests}

The authors declare that have no competing interests.

Received: 13 February 2015 Accepted: 2 November 2015

Published online: 05 November 2015

\section{References}

1. Jemal A, Bray F, Center MM, Ferlay J, Ward E, Forman D. Global cancer statistics. CA Cancer J Clin. 2011;61:69-90.

2. Shang N, Arteaga M, Zaidi A, Stauffer J, Cotler SJ, Zeleznik-Le NJ, Zhang J, Qiu W. FAK is required for c-Met/beta-catenin-driven hepatocarcinogenesis. Hepatology. 2015;61:214-26.

3. Zhang Y, Li T, Guo P, Kang J, Wei Q, Jia X, Zhao W, Huai W, Qiu Y, Sun L, Han L. MiR-424-5p reversed epithelial-mesenchymal transition of anchorageindependent HCC cells by directly targeting ICAT and suppressed HCC progression. Sci Rep. 2014;4:6248.

4. Raza A, Sood GK. Hepatocellular carcinoma review: current treatment, and evidence-based medicine. World J Gastroenterol. 2014;20:4115-27.

5. Johnson PJ. Non-surgical treatment of hepatocellular carcinoma. HPB (Oxford). 2005;7:50-5.

6. Llovet JM, Ricci S, Mazzaferro V, Hilgard P, Gane E, Blanc JF, de Oliveira AC, Santoro A, Raoul JL, Forner A, et al. Sorafenib in advanced hepatocellular carcinoma. N Engl J Med. 2008;359:378-90.

7. Branscombe TL, Frankel A, Lee JH, Cook JR, Yang Z, Pestka S, Clarke S. PRMT5 (Janus kinase-binding protein 1) catalyzes the formation of symmetric dimethylarginine residues in proteins. J Biol Chem. 2001;276:32971-6.

8. Ren J, Wang Y, Liang Y, Zhang Y, Bao S, Xu Z. Methylation of ribosomal protein $\mathrm{S} 10$ by protein-arginine methyltransferase 5 regulates ribosome biogenesis. J Biol Chem. 2010;285:12695-705.

9. Pal S, Vishwanath SN, Erdjument-Bromage H, Tempst P, Sif S. Human SWI/ SNF-associated PRMT5 methylates histone $\mathrm{H} 3$ arginine 8 and negatively regulates expression of ST7 and NM23 tumor suppressor genes. Mol Cell Biol. 2004;24:9630-45.

10. Zhao Q, Rank G, Tan YT, Li H, Moritz RL, Simpson RJ, Cerruti L, Curtis DJ, Patel DJ, Allis CD, et al. PRMT5-mediated methylation of histone H4R3 recruits DNMT3A, coupling histone and DNA methylation in gene silencing. Nat Struct Mol Biol. 2009;16:304-11.

11. Cho EC, Zheng S, Munro S, Liu G, Carr SM, Moehlenbrink J, Lu YC, Stimson L, Khan O, Konietzny R, et al. Arginine methylation controls growth regulation by E2F-1. EMBO J. 2012;31:1785-97.

12. Gu Z, Gao S, Zhang F, Wang Z, Ma W, Davis RE, Wang Z. Protein arginine methyltransferase 5 is essential for growth of lung cancer cells. Biochem J. 2012:446:235-41.

13. Pal S, Baiocchi RA, Byrd JC, Grever MR, Jacob ST, Sif S. Low levels of miR92b/96 induce PRMT5 translation and H3R8/H4R3 methylation in mantle cell lymphoma. EMBO J. 2007;26:3558-69.

14. Powers MA, Fay MM, Factor RE, Welm AL, Ullman KS. Protein arginine methyltransferase 5 accelerates tumor growth by arginine methylation of the tumor suppressor programmed cell death 4. Cancer Res. 2011;71:5579-87.

15. Wang L, Pal S, Sif S. Protein arginine methyltransferase 5 suppresses the transcription of the RB family of tumor suppressors in leukemia and lymphoma cells. Mol Cell Biol. 2008;28:6262-77.

16. Al-Aynati MM, Radulovich N, Riddell RH, Tsao MS. Epithelial-cadherin and beta-catenin expression changes in pancreatic intraepithelial neoplasia. Clin Cancer Res. 2004;10:1235-40.

17. Cui Y, Wu J, Zong M, Song G, Jia Q, Jiang J, Han J. Proteomic profiling in pancreatic cancer with and without lymph node metastasis. Int I Cancer. 2009;124:1614-21.

18. Bello E, Colella G, Scarlato V, Oliva P, Berndt A, Valbusa G, Serra SC, D'Incalci M, Cavalletti E, Giavazzi R, et al. E-3810 is a potent dual inhibitor of VEGFR and FGFR that exerts antitumor activity in multiple preclinical models. Cancer Res. 2011;71:1396-405.

19. Zhang B, Dong S, Cen X, Wang X, Liu X, Zhang H, Zhao X, Wu Y. Ampelopsin sodium exhibits antitumor effects against bladder carcinoma in orthotopic xenograft models. Anticancer Drugs. 2012;23:590-6.

20. Epstein Shochet G, Tartakover Matalon S, Drucker L, Pomeranz M, Fishman A, Rashid G, Oron-Karni V, Pasmanik-Chor M, Lishner M. Hormonedependent placental manipulation of breast cancer cell migration. Hum Reprod 2012;27:73-88.

21. Wang L, Yao J, Zhang X, Guo B, Le X, Cubberly M, Li Z, Nan K, Song T, Huang C. miRNA-302b suppresses human hepatocellular carcinoma by targeting AKT2. Mol Cancer Res. 2014;12:190-202.

22. Lei Y, Huang K, Gao C, Lau QC, Pan H, Xie K, Li J, Liu R, Zhang T, Xie N, et al. Proteomics identification of ITGB3 as a key regulator in reactive oxygen species-induced migration and invasion of colorectal cancer cells. Mol Cell Proteomics. 2011;10(M110):005397.

23. Zhang J, Shan WF, Jin TT, Wu GQ, Xiong XX, Jin HY, Zhu SM. Propofol exerts anti-hepatocellular carcinoma by microvesicle-mediated transfer of miR-142-3p from macrophage to cancer cells. J Trans Med. 2014;12:279.

24. Yan F, Alinari L, Lustberg ME, Martin LK, Cordero-Nieves HM, BanasavadiSiddegowda Y, Virk S, Barnholtz-Sloan J, Bell EH, Wojton J, et al. Genetic validation of the protein arginine methyltransferase PRMT5 as a candidate therapeutic target in glioblastoma. Cancer Res. 2014;74:1752-65.

25. Yang $Y$, Bedford MT. Protein arginine methyltransferases and cancer. Nat Rev Cancer. 2013;13:37-50.

26. Cheng D, Yadav N, King RW, Swanson MS, Weinstein EJ, Bedford MT. Small molecule regulators of protein arginine methyltransferases. J Biol Chem. 2004:279:23892-9.

27. Zhang B, Dong S, Zhu R, Hu C, Hou J, Li Y, Zhao Q, Shao X, Bu Q, Li H, et al. Targeting protein arginine methyltransferase 5 inhibits colorectal cancer growth by decreasing arginine methylation of elF4E and FGFR3. Oncotarget. 2015;6:22799-811. 
28. Andreu-Perez P, Hernandez-Losa J, Moline T, Gil R, Grueso J, Pujol A, Cortes J, Avila MA, Recio JA. Methylthioadenosine (MTA) inhibits melanoma cell proliferation and in vivo tumor growth. BMC Cancer. 2010;10:265.

29. Ansorena E, Garcia-Trevijano ER, Martinez-Chantar ML, Huang ZZ, Chen L, Mato JM, Iraburu M, Lu SC, Avila MA. S-adenosylmethionine and methylthioadenosine are antiapoptotic in cultured rat hepatocytes but proapoptotic in human hepatoma cells. Hepatology. 2002;35:274-80.

30. LiTW, Zhang Q, Oh P, Xia M, Chen H, Bemanian S, Lastra N, Circ M, Moyer MP, Mato JM, et al. S-Adenosylmethionine and methylthioadenosine inhibit cellular FLICE inhibitory protein expression and induce apoptosis in colon cancer cells. Mol Pharmacol. 2009;76:192-200.

31. Jansson M, Durant ST, Cho EC, Sheahan S, Edelmann M, Kessler B, La Thangue NB. Arginine methylation regulates the 553 response. Nat Cell Biol. 2008;10:1431-9.

32. Tanaka H, Hoshikawa Y, Oh-hara T, Koike S, Naito M, Noda T, Arai H, Tsuruo T, Fujita N. PRMT5, a novel TRAIL receptor-binding protein, inhibits TRAILinduced apoptosis via nuclear factor-kappaB activation. Mol Cancer Res. 2009;7:557-69.

33. Shen $G$, Jia H, Tai Q, Li Y, Chen D. miR-106b downregulates adenomatous polyposis coli and promotes cell proliferation in human hepatocellular carcinoma. Carcinogenesis. 2013;34:211-9.
34. Huang H, Fujii H, Sankila A, Mahler-Araujo BM, Matsuda M, Cathomas $\mathrm{G}$, Ohgaki H. Beta-catenin mutations are frequent in human hepatocellular carcinomas associated with hepatitis C virus infection. Am J Pathol. 1999;155:1795-801.

35. Angers S, Moon RT. Proximal events in Wnt signal transduction. Nat Rev Mol Cell Biol. 2009;10:468-77.

36. Tetsu O, McCormick F. Beta-catenin regulates expression of cyclin D1 in colon carcinoma cells. Nature. 1999;398:422-6.

37. Nishida N, Fukuda Y, Komeda T, Kita R, Sando T, Furukawa M, Amenomor M, Shibagaki I, Nakao K, Ikenaga M, et al. Amplification and overexpression of the cyclin D1 gene in aggressive human hepatocellular carcinoma. Cancer Res. 1994;54:3107-10.

38. LeBlanc SE, Konda S, Wu Q, Hu YJ, Oslowski CM, Sif S, Imbalzano AN. Protein arginine methyltransferase 5 (Prmt5) promotes gene expression of peroxisome proliferator-activated receptor gamma2 (PPARgamma2) and its target genes during adipogenesis. Mol Endocrinol. 2012;26:583-97.

39. Luo M. Current chemical biology approaches to interrogate protein methyltransferases. ACS Chem Biol. 2012;7:443-63.

40. Yost JM, Korboukh I, Liu F, Gao C, Jin J. Targets in epigenetics: inhibiting the methyl writers of the histone code. Curr Chem Genomics. 2011;5:72-84

41. Bedford MT, Richard S. Arginine methylation an emerging regulator of protein function. Mol Cell. 2005;18:263-72.

\section{Submit your next manuscript to BioMed Central and take full advantage of:}

- Convenient online submission

- Thorough peer review

- No space constraints or color figure charges

- Immediate publication on acceptance

- Inclusion in PubMed, CAS, Scopus and Google Scholar

- Research which is freely available for redistribution

Submit your manuscript at

www.biomedcentral.com/submit

() BioMed Central 